\title{
Edad Áurea y res publica: en torno a las fuentes clásicas del utopismo de Vasco de Quiroga
}

\section{Golden Age and res publica: Around the Classical Sources of Utopianism Vasco de Quiroga}

\author{
Guillermo GARCÍA UREÑA \\ Texas A\&M University \\ ggurena@gmail.com
}

Recibido: 10/11/2012

Aceptado: 20/02/2014

\section{Resumen}

En el presente escrito trataremos las fuentes clásicas -explícitas e implícitas-en la obra de Vasco de Quiroga, bajo la consideración de que es a partir de cierta interpretación de estas fuentes desde donde surgirá, en conjunción con el cristianismo, no sólo una determinada concepción del mundo y de la historia, sino también una concreta praxis política como alternativa a las encomiendas. De esta manera, se presenta un modo de pensar, desde la tradición de pensamiento hispana y en virtud del diálogo con el mundo clásico, la problemática cuestión de una correcta res publica indiana.

Palabras clave: Vasco de Quiroga, Mito de las edades del hombre, Edad de Oro, Luciano, Virgilio, encomiendas, Nuevo Mundo.

\begin{abstract}
In this paper we discuss the classical sources -explicit and implicit- in Vasco de Quiroga's work, considering that it is from a concrete interpretation of these sources, in conjunction with Christianity, where not only a particular conception of the world and history emerges, but also a concrete political practice, in order to give an alternative to the encomiendas. Thus, it is presented a way of thinking within the Hispanic tradition of ideas, in virtue of the dialogue with the classical world, the problematic issue of a right res publica indiana.
\end{abstract}


Keywords: Vasco de Quiroga, Myth of the Ages of Man, Golden Age, Lucian, Virgil, encomiendas, New World.

\section{Introducción}

En el presente artículo nos atendremos al uso que de las fuentes clásicas hace Vasco de Quiroga, tanto en referencia directa a la tradición grecolatina (Luciano de Samosata, Virgilio), como en referencia mediada por autores coetáneos (Antonio de Guevara, Moro). El cometido último de este trabajo está en analizar las fuentes clásicas del mito de las Edades y de la Utopía como elementos pragmáticamente claves de la fundamentación práctica de Quiroga. En este análisis, por tanto, no se tratará la tradición jurídica o teológica (bíblica, patrística), ni en concreto las influencias contemporáneas o cercanas a su formación (el conciliarismo de Gerson y el de Basilea, el pensamiento de las Comunidades o su experiencia en Orán y el entrecruce de las tres religiones), sino que, por razones expositivas y de extensión, se pospondrán a otra publicación ya en curso que toma como base el presente trabajo.

Las fuentes clásicas resultan especialmente cruciales para la cuestión que nos ocupa puesto que fundamentan el posicionamiento de Quiroga frente a otros personajes renacentistas en el debate suscitado en torno a las Indias, así como lo incorporan al tópos literario de la paradisíaca edad de oro ${ }^{1}$ que, en contacto con América, tendrá una muy fructífera refundición de implicaciones históricas y políticas. Este mito acerca de las edades del hombre es tratado por doquier, llegando hasta la Grecia arcaica con Hesíodo, pero lo relevante en el debate en el que está inscrita la obra de Quiroga son unas pocas obras clásicas, principalmente Luciano de Samosata y Virgilio, a partir de las cuales autores renacentistas como Tomás Moro y Antonio de Guevara se servirán para construir su pensamiento, modificando el sentido original del mito en el que la edad de oro refleja un pasado idílico y perdido, en otros dos tipos de narraciones que encontramos, respectivamente, en Moro y Guevara: en el primero, la edad de oro se desplaza de un tiempo pasado a un espacio lejano idílico, que sería el caso de la atlántica Insula Utopia; en el segundo, la edad de oro se encuentra no en tiempo ni en espacio lejano, sino en aspectos o estratos de la sociedad más humildes y cercanos al campo, como es el ejemplo del relato de El villano del Danubio $^{2}$. Ahora bien, estas modificaciones del mito no estriban en el desplazamiento del sentido temporal a otro sentido, pues tales variaciones pueden aparecer en otros

\footnotetext{
${ }^{1}$ P. Serrano Gassent, Vasco de Quiroga. Utopía y derecho en la conquista de América, Madrid, Fondo de Cultura Económica, 2001, p. 174.

${ }^{2}$ Para la influencia de Moro sobre Guevara, las fuentes de "el villano del Danubio" o los usos de la edad de oro, véase S. A. Vosters, Antonio de Guevara y Europa, Salamanca, Ediciones Universidad de Salamanca, 2009.
} 
textos clásicos, sino que lo crucial está en que obviar el sentido temporal posibilita que tal edad áurea se esté dando de facto. Es en este sentido donde la utilización del mito de las edades cobra mayor fuerza en tanto que no sólo sirve como crítica al estado de cosas actual, sino que además apunta a una solución del mismo ${ }^{3}$. Pues bien, este modo de habérselas con la tradición será recogido por Vasco de Quiroga, quien cita tanto a Moro como a Guevara ${ }^{4}$, y en el que la mítica edad de oro no es sino el tangible -y a partir de ahora histórico- Nuevo Mundo, donde la crítica tendrá el carácter anfibológico de denunciar la actuación hispana en relación con los indios así como también advertir de la pobreza moral en la que se encuentra el propio cristianismo del Viejo Mundo.

Asimismo, las implicaciones sociopolíticas y teológicas que se derivaban del uso de las fuentes clásicas por parte de Quiroga se confrontaban con otros autores hispanos del momento ${ }^{5}$. El proyecto quiroguiano aunaba en su seno la misión evangelizadora con un programa político sin el cual el arraigo del cristianismo se tornaría imposible. Esta llamada "policía mixta", respondía a la necesidad de, por una parte, solventar el conflicto de la esclavitud, ya sea por supuesta guerra justa, ya sea por la pretendida herencia de esclavos del anterior orden político previo a la llegada de los españoles, $y$, por otra parte, incitar un cambio en el planteamiento económico imperial, que pasaba por considerar el Nuevo Mundo desde el imaginario romano de la provincia y no desde los excesos de la encomienda, para lo que era urgente la instauración de unas bases sólidas para la fundación de diversas res publicas christianas autónomas. De este modo se pugnaba, en primer lugar, contra la tesis de la guerra justa, ya discutida por Bartolomé de las Casas contra Juan Ginés de Sepúlveda, para

\footnotetext{
${ }^{3}$ Con gran claridad resume Francesca Cantú: "el presupuesto crítico del que parte Quiroga es el de que la sociedad española en América constituye la anti-utopía de la posible utopía americana". F. Cantú, "América y utopía en el siglo XVI" en Cuadernos de Historia Moderna. Anejos, n 1 , 2002, p. 45-64 (p. 50).

${ }^{4}$ Conviene hacer algunas menciones sobre la circulación de los textos y el acceso a los mismos que podía tener Vasco de Quiroga para remarcar el análisis histórico de las fuentes. Además de su sólida formación en los dos derechos, las abundantes citas patrísticas, a Gerson o a la Utopía misma nos llevan a pensar que Quiroga tenía acceso a la biblioteca de Juan de Zumárraga, primer obispo de México. Warren incluso apunta la posibilidad de que el ejemplar de la Utopía que fuera de Zumárraga, hoy en los fondos de la University of Texas en Austin, fuese anotado en el margen por el mismo Quiroga, si bien la comparación de la grafía no es definitoria al respecto. F. B. Warren, Vasco de Quiroga and his Pueblo-Hospitals of Santa Fe, Washington D. C., Academy of American Franciscan History, 1963, p. 30.

${ }^{5}$ A modo de comprensión y contextualización del complejo debate en torno a la legitimidad del poder hispánico sobre el Nuevo Mundo y sobre los indios, consideramos pertinente citar el trabajo aún inédito de José Luis Villacañas Berlanga, "América en el pensamiento hispánico del siglo XVI", que por gentileza del autor hemos podido consultar, y que formará parte de una obra mayor sobre la historia política hispana en época de Carlos V.
} 
quien se debe imponer de entrada el dominio militar español sobre el indio antes que intentar la evangelización "pues si se hubiese de esperar a que ellos se instruyesen en la naturaleza, costumbres e inteligencia de los españoles y de las suyas, de la diferencia de ambos pueblos, del derecho de mandar y obedecer, de la diferencia, honestidad y verdad de moral y religión, el tiempo concedido se alargaría hasta el infinito y sería en vano, pues esto no puede conocerse sino después de aceptado nuestro imperio..." ". En segundo lugar, contra la posibilidad de esclavizar tras la supuesta guerra justa, como encontramos en Matías de Paz: "parece que el Rey de España puede tener y poseer con despótico principado a los mencionados indios, porque todo aquél que puede subyugar por medio de la guerra alguna patria, provincia o reino, puede, con igual licitud, reducir a servidumbre a sus habitantes caso de apresarlos"7. En tercer lugar, también se está discutiendo contra la supuesta herencia de esclavos naturales, como alega Juan López de Palacios Rubios: “aunque estos isleños no perdieron por esta causa [la guerra justa] su primitiva libertad, [...] algunos de ellos son tan ineptos e incapaces, que no saben en absoluto gobernarse, por lo cual, en sentido lato, pueden ser llamados esclavos, como nacidos para servir y no para mandar, según lo trae el Filósofo, en el lib. I de su Política" ${ }^{\text {. }}$

La postura de Quiroga frente a los conquistadores se podría condensar en la siguiente cita: "Jesucristo, rey de reyes, a quien ha sido dada toda potestad en el cielo y en la tierra, envió para la conquista del mundo no soldados con armamento, sino predicadores santos, como ovejas entre lobos. Por eso, ni siquiera en el Antiguo Testamento, cuando había que tomar con mano armada la tierra de infieles, en ninguna parte leo que se haya declarado la guerra a alguien por el simple hecho de no ser creyente" . Además, como ya hemos mencionado, la conquista mediante los predicadores había de establecerse en ciudades: "porque tengo por muy cierto para mí que sin este recogimiento de ciudades grandes que estén ordenadas y cumplidas de todo lo necesario, en buena y católica policía y conforme a la manera de esto, ninguna buena conversión general ni aun casi particular ni perpetuidad ni conservación ni buen tratamiento ni ejecución de las ordenanzas ni de justicia en esta tierra ni entre estos naturales puede esperar ni haber"10.

\footnotetext{
${ }^{6}$ J. Ginés de Sepúlveda, Demócrates Segundo o de las justas causas de la guerra contra los indios, Madrid, Consejo Superior de Investigaciones Científicas, 1984, § 15, 715.

${ }^{7}$ Matías de Paz, Del dominio de los Reyes de España sobre los indios, México, Fondo de Cultura Económica, 1954, p. 213.

${ }^{8}$ J. López de Palacios Rubios, De las Islas del mar Océano, México, Fondo de Cultura Económica, 1954,p. 37.

${ }_{9}^{9}$ Vasco de Quiroga, Información en derecho, edición de Paz Serrano Gassent, Madrid, Dastin, 2002 , p. 95.

${ }^{10}$ Ibidem, p. 106.
} 
Los argumentos en contra de la esclavitud son claros: allí donde se justifica la esclavitud por motivos de guerra justa, Quiroga indica que tal situación no es ius belli sino defensa legítima ante la injusticia de los conquistadores españoles: vim vi repellere licet omnes leges omniaque iura proclamant ("todas las leyes y derecho proclaman que es lícito repeler la fuerza con la fuerza"11); por otra parte, allí donde se pretende transferir los esclavos naturales u originarios del orden indio al orden español, Quiroga negará la existencia de tales esclavos naturales. No estamos ante la noción de esclavitud de cuño romano, sino ante una prestación de servicios: "esta manera y género de esclavos que nosotros tenemos que pierden la libertad e ingenuidad, ciudad y familia, que es la máxima capitis disminución y lo que se requiere que concurra en ellos de necesidad para ser verdaderos esclavos entre nosotros, que no son reputados nihil de derecho civil, y para que los hijos de la madre esclava sean esclavos y para que estén en poder del señor y no puedan testar ni disponer, ni tener hacienda ni cosa alguna que sea suya, como son los que son esclavos acerca de nosotros y como lo eran cerca de los ciudadanos romanos, cuyas leyes en esto tenemos", sino que "yo entre éstos no la veo, antes lo veo todo lo contrario y que lo retienen todo: libertad, familia y ciudad o lugar, y que no mudan estado ni condición, y que no pierden cosa de él, ni concurren en ellos las condiciones de esclavos, sino de libres"12. Se trata pues, de locatio operarum in perpetuum ("alquiler del trabajo a perpetuidad").

\section{Las "Saturnales" de Luciano: el paganismo a favor de una modélica Res Pu- blica Christiana}

El debate en torno a las Indias despliega, junto con las disputas acerca de la legitimidad del dominio sobre el Nuevo Mundo, el problema de la consideración que se tiene sobre el indio, o en términos más generales, sobre el otro del europeo. La relación con el indio será, sin duda, unilateral, y rara vez se hablará de éste de un modo distinto que como productor o artesano, apenas nunca como verdadero interlocutor. Esto marcará, siguiendo a Todorov ${ }^{13}$, una tipología de las relaciones con el otro que excluirá mayormente la apreciación del indio como sujeto. Todorov distingue tres planos de relación: axiológico o valorativo, praxeológico, que se refiere a la acción de acercamiento o distanciamiento y a la asimilación de una cultura a la otra, y, finalmente, epistemológico. Según esta tipología se dará la paradójica situación de que en los autores que tienen una posición valorativa positiva, así como

\footnotetext{
${ }^{11}$ Ibidem, p. 118.

${ }^{12}$ Ibidem, p. 127.

${ }^{13}$ S. Todorov, La conquista de América. El problema del otro, Madrid, Siglo XXI, 2010, p. 195 y ss.
} 
de acercamiento y asimilación de los indios al cristianismo, se muestra un mayor desconocimiento de los mismos, cuyos rasgos quedan aplanados bajo las características de "buenos" o "propicios" al cristianismo. De esta manera se facilita la asimilación del indio a la cultura cristiana y, por tanto, su posible evangelización y la negativa a esclavización. En cambio, cuando el autor defienda el dominio o la esclavitud del indio, los rasgos distintivos, pese a que son por lo general pobres, serán más descriptivos para marcar la diferencia -e inferioridad- de su cultura. A este respecto, Todorov señala que lo original de Quiroga es que la asimilación del indio, si bien está encaminada a la defensa de la evangelización, no lo es solamente con respecto a la cultura cristiana, sino en relación a un tercero que es la prole áurea de las Saturnales. Por ello dice: "no ve en ellos lo que son, sino lo que él quisiera que fueran"14. Cuestión en la que disentimos pues, si por una parte es cierto que el conocimiento que da de los indios desde un punto de vista antropológico o etnológico es bastante limitado, ello no se debe -al menos exclusivamente- a que aplique doquiera un anquilosado esquematismo, sino que la referencia mítica va encaminada a apoyar los intereses político-pragmáticos de su argumentación, que no eran otros que la anulación de la Real Cédula de 1534, según la cual se permitía la esclavitud de los indios, y el restablecimiento de la prohibición del año $30^{15}$. Además, la comparación entre el indio y la edad de oro aparece al final de la Información en Derecho, tras una larga y repetitiva exposición de la invalidez del ius belli y de la herencia de esclavos naturales, para alabar la buena disposición de los indios, a la vez que advertir la facilidad de su completa pérdida si la política hispana en el Nuevo Mundo no varía y no se les introduce en comunidades jurídicas y cristianas ${ }^{16}$. Ante lo cual habría que concluir que no es tanto desconocimiento de los indios por parte de Quiroga, cuanto un modo de referencia metafórica ${ }^{17}$, impropio desde un punto de vista descriptivo, pero que haciendo uso del mito puede resigni-

\footnotetext{
${ }^{14}$ Ibidem, p. 204. En este punto concreto el acercamiento que tiene Todorov al texto histórico obvia la conexión de estos escritos históricos y jurídicos con la retórica y la ejemplaridad. A este respecto resulta fundamental la obra de Rubial García y la relación que establece entre la escritura de la historia, la construcción de una cierta memoria y su proyección ejemplar para el futuro. Véase, por caso, A. Rubial García, "Ángeles en carne mortal. Viejos y nuevos mitos sobre la evangelización de Mesoamérica”, en Signos Históricos, Revista de la UAM Itztapalapa, n 7, 2002, pp. 19-51.

${ }^{15}$ S. Zavala, "Ideario de Vasco de Quiroga", en Recuerdo de Vasco de Quiroga, México, Porrúa, 1987, p. 40.

${ }^{16}$ P. Hermida Lazcano, “Topografía de una utopía”, en Revista de Indias, Vol. LV, 204, 1995, pp. 357-390 (p. 372).

${ }^{17}$ P. Ricoeur, La metáfora viva, Madrid, Trotta-Cristiandad, 2001, p. 287 y ss. A este respecto también hay que tener en cuenta la crítica de Blumenberg a la consideración, por caso, cartesiana, del mito o la metáfora como residuos en el camino a la plena logicidad. H. Blumenberg, Paradigmas para una metaforología, Madrid, Trotta, 2003, p. 44.
} 
ficar la realidad concreta a la que se refiere con una marcada finalidad política, como veremos a continuación.

La referencia a las Saturnales de Luciano de Samosata ${ }^{18}$ se produce en el proceso de defensa de la labor evangelizadora frente al uso del indio como mano de obra esclava, especialmente en lo que respecta al trabajo en las minas cuyas condiciones eran muy duras y paupérrimas ${ }^{19}$. Para ello se describe al indio no sólo como alguien en muchos aspectos receptivo hacia las costumbres cristianas, sino incluso también como poseedor de un carácter más propicio a la verdadera esencia cristiana que "entre nosotros de hierro y de acero y peor" ${ }^{20}$, pues los indios son "gente simplicísima y docilísima y la mejor y más apta para nuestra religión cristiana" ${ }^{21}$. Esta predisposición del indio hacia la religión cristiana también se encuentra en Pedro Mártir de Anglería: "a la puesta del sol, hecha la señal de la salutación angélica, arrodillándose los nuestros como cristianos, ellos hacían lo mismo. De cualquier modo que veían a los cristianos venerar la cruz, la adoraban ellos" ${ }^{22}$. De hecho, dos décadas antes de la llegada, en 1531, de Vasco de Quiroga a México, Mártir de Anglería ya había considerado la sociedad del indio como perteneciente a la edad de oro: "tienen ellos por cierto que la tierra, como el sol y el agua, es común, y que no debe haber entre ellos mío y tuyo, semillas de todos los males, pues se contentaban con tan poco que en aquel vasto territorio más sobran campos que no le falta a nadie nada. Para ellos es la Edad de Oro" 23 . La enumeración de rasgos de los indios en comparación con la edad de oro es copiosa en ambos autores: "simplicidad, bondad, obediencia, humildad...", y "menosprecio de todo lo superfluo", en Quiroga, así como "de su natural veneran al que es recto; tienen por malo y perverso al que se complace en hacer injuria a cualquiera" ${ }^{24}$, en Mártir de Anglería.

\footnotetext{
${ }^{18}$ Quizá el uso de Luciano de Samosata como autoridad no sea el más apropiado para la labor de Quiroga, habida cuenta del común trato cómico que hace de los temas mitológicos y que también se ve en las Saturnales. En este caso, Quiroga parece obviar el tono burlesco de Luciano.

${ }^{19}$ Es de resaltar, como cita Todorov, que Fray Toribio de Benavente, Motolinía, enumera al comienzo de su Historia diez plagas que Dios ha enviado como castigo a las Indias, de las cuales tres son producidas directamente por las minas de oro. Citamos un ejemplo estremecedor: "de los esclavos que murieron en las minas fue tanto el hedor, que causó pestilencia, en especial en las minas de Guaxaca, en las cuales media legua a la redonda y mucha parte del camino, apenas se podía pisar sino sobre hombres muertos o sobre huesos. Y eran tantas las aves y cuervos que venían a comer sobre los cuerpos muertos, que hacían gran sombra al sol". Fray Toribio de Benavente, Historia de los indios de la Nueva España, Madrid, Alianza, 1988, p. 60.

${ }^{20}$ Quiroga, op. cit., p. 209.

${ }^{21}$ Ibidem, p. 208.

${ }^{22}$ P. Mártir de Anglería, Décadas del Nuevo Mundo, Madrid, Polifemo, 1989, p. 12.

${ }^{23}$ Ibidem, p. 38.

${ }^{24}$ Ibidem.
} 
Una vez realizada la identificación con la edad de oro, hay otra cuestión, en nada baladí, que implica tal comparación: cita Quiroga una frase de Luciano que dice "igualdad para todos: esclavos y libres. Porque, dice allí Saturno, cuando yo reinaba nadie era esclavo" 25 , del mismo modo que entre los indios no hay "siervos ni esclavos verdaderos, sino sirvientes" ${ }^{26}$. De esta manera, el rechazo de la esclavitud busca encontrar en la antigüedad clásica, pagana y esclavista, un apoyo desde la conciencia de la empresa evangelizadora confiada por la bula papal. Tal empresa no puede verse en modo alguno interferida por intereses económicos esclavistas, no sólo porque no hay guerra justa ni esclavos naturales, sino porque el Nuevo Mundo está en la edad de oro y, por ende, sus gentes están más orientadas a Dios por su carácter que los propios españoles.

Ahora bien, el hecho de que los relatos míticos hablen de una edad de oro que se corrompió y devino en la edad de hierro marcada por la codicia, supone que del mismo modo que el Viejo Mundo se pervirtió, podría pervertirse el Nuevo Mundo. $\mathrm{Al}$ respecto dice Mártir de Anglería: "sin embargo, también les atormenta la ambición del mando y se arruinan mutuamente con guerras, de la cual peste no creo que se viera inmune de modo alguno la edad de oro, sin que en aquel tiempo anduvieran los mortales con el dame y el no te doy" ${ }^{27}$. Quiroga era bien consciente de este problema. " $¡ O$ Oh cuán gran culpa nuestra será, si supiere a la pega de nuestras malas y mal cristianas costumbres, y no a las buenas que entre ellos tan fácil se podrían introducir e injerir" ${ }^{28}$. De hecho, tal dificultad se encontraba también en el mismo texto de Luciano, si bien el tono general es de parodia. Así cita Quiroga: "Sacerdote: ¿Pero qué

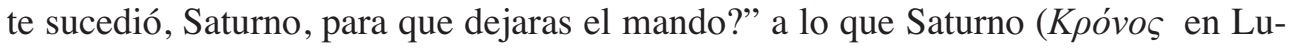
ciano) responde (citamos una parte concreta) "no tenía ya fuerzas bastantes para castigar los excesivos delitos de esta edad". Entonces, la edad de oro del Nuevo Mundo está abocada a la ruina, más y cuando entran en escena personajes de la edad de hierro; sin embargo, hay un modo de controlar esta debacle y es en virtud del establecimiento de unas rectas ordenanzas. Pues del mismo modo que una buena institución puede ver su destrucción en una constante negligencia por parte de sus usuarios, la buena disposición de carácter puede desdibujarse si no hay alguna instancia regula-

\footnotetext{
${ }^{25}$ Quiroga cita a partir de la traducción latina de Tomás Moro que dice "aequalitas omnibus servis aeque ac liberis. Nec enim me regnante quisquam erat servus". El texto de Luciano dice así: "ioo-

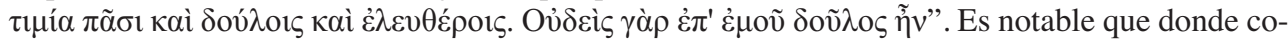

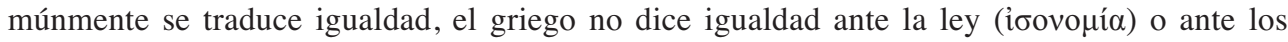

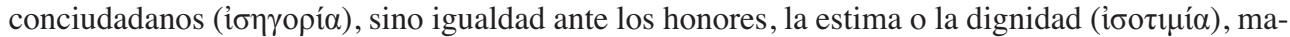
tices estos que con la traducción latina se pierden. Lucian, Saturnalia, en "Lucian in eight volumes (vol. VI), Great Britain, Loeb Classical Library, 1959, §7, p. 98.

${ }^{26}$ Quiroga, op. cit., p. 212.

${ }^{27}$ Mártir de Anglería, op. cit., p. 23.

${ }^{28}$ Quiroga, op.cit., p. 210.
} 
tiva que ponga un marco legal, en especial cuando hay elementos amenazantes como los conquistadores. Dice al respecto Quiroga: "[los indios tienen] flojedad y descuido, lo cual conviene que se les quite con alguna buena orden de república y policía, porque, aunque dejados así como ahora están, para su miseria y buen contentamiento sean bastantes, para nuestro fausto y soberbia cierto no lo son, y primero se acabarán que lo sean, si alguna grande industria no se les da" ${ }^{29}$. El argumento no deja lugar a dudas: la misión evangelizadora es muy factible si las costumbres cristianas, a las que tan bien están orientados los indios, se enmarcan en el ámbito de una res publica: "pues si es verdad, como lo es, que la edad dorada de aquéllos entre estos naturales casi en todo y por todo la tenemos para poder introducir e imprimir en ellos una cera muy blanda, y hombres de tan buen, sana y simple voluntad y obediencia, todo cuanto bueno quisiéremos sin resistencia alguna y la doctrina cristiana y más propia y aparejada para injerirse en ella en gente de tal calidad por las condiciones que dichas son que más en ellas reinan..." ${ }^{30}$. La conclusión que se deriva de estas argumentaciones es que si la evangelización no se produce de una manera satisfactoria ello no será por los indios, que son cera blanda, sino por el mismo interés económico de los conquistadores españoles.

Cabría preguntarse ahora qué ordenanzas serán aquellas que se conjuguen bien con la gente de oro conformando la cosa pública; Quiroga recurre a la obra de Tomás Moro, que recordemos, por ser más esclarecedor, en su título completo: De optimo rei publicae statu deque nova insula Utopia, donde nova insula bien puede ser intercambiada en el pensamiento de Quiroga por novus orbis, si bien el carácter de la res publica es el mismo. Además, la referencia a Luciano está íntimamente relacionada con la lectura de Moro, como apunta el mismo Quiroga ${ }^{31}$ : "tradujo algunas cosas de Luciano de griego en latín, donde, como dicho tengo, se ponen las leyes y ordenanzas y costumbres de aquella edad dorada" 32 . De hecho, creía que la Utopía de Moro era el modelo ajustado para el caso del Nuevo Mundo, y en esa línea escribirá las Ordenanzas: "de donde como de dechado se sacó el de mi parecer, varón ilustre y de genio más que humano, el arte y manera de las gentes simplicísimas de este Nuevo Mundo, y pareciéndole que en todo eran conformes y semejantes a aquéllas de aquella gente de oro de aquella primera edad dorada, sacó para el único remedio de él y

\footnotetext{
${ }^{29}$ Ibidem, p. 214.

${ }^{30}$ Ibidem.

${ }^{31}$ La conexión entre estos tres autores se refleja en las traducciones que se hicieron: por una parte, Quiroga lee las Saturnales por la traducción de Moro, pero, por otra parte, el mismo Quiroga traducirá parte de la Utopía de Moro al castellano, lo cual, pese a que se haya perdido tal traducción, haría de Quiroga el primer traductor de Moro al castellano. Zavala, "En el camino del pensamiento y las lecturas de Vasco de Quiroga", en op. cit., p. 294.

${ }^{32}$ Quiroga, op. cit., p. 218.
} 
de ellas, como inspirado del Espíritu Santo, de las costumbres de aquéllas, las ordenanzas y muy buen estado de república en que se podrían guardar, conservar e industriar muy mejor y más fácilmente sin comparación que por otra manera alguna ni estado que se les pueda dar, que no les sea tan natural ni tan conforme a su arte, manera y condición..."33.

Esta policía mixta de los hospitales ${ }^{34}$ se configura en base a la unidad familiar patriarcal, con un sistema productivo principalmente basado en la agricultura, en régimen de propiedad comunal y sin uso de dinero; hasta aquí se reproduce el relato de Moro, pero hay que resaltar dos relevantes novedades: en primer lugar, siguiendo la letra de la Utopía, los cargos de responsabilidad son elegidos de entre los patres familias, lo que supone un aspecto muy notable en lo que respecta a las intenciones organizativas, puesto que intenta que el indio haga suya esa comunidad ${ }^{35}$, en lo que Martínez Baracs ve como una propuesta que buscaba ser aún provechosa para los señores michoacanos ${ }^{36}$; en segundo lugar, hay una distinción respecto del texto de Moro en lo tocante al sacerdocio que refleja el agustinismo político de Quiroga, pues en las Ordenanzas hay un cargo no electivo dotado del mayor poder político y religioso: se trata del Rector. De esta manera se abogaba por una evangelización profunda que se centraba en el episcopalismo y el gobierno de ciudades indias autónomas, lo que facilitó la posibilidad de llevar el proyecto acabo al depender únicamente de las tierras adquiridas por el obispo de Michoacán, y no pretenderlo en otros ambientes en los que confluyan numerosos intereses opuestos como conquistadores y encomenderos.

\footnotetext{
${ }^{33}$ Ibidem.

${ }^{34}$ Hermida Lazcano recuerda, de mano de Covarrubias, que policía designa la "política, la ciencia y modo de gobernar la ciudad y república". Citemos, asimismo, una acepción que da de hospital: "lugar pío donde se reciben los peregrinos pobres, vel latine hospicium vel hospitale. Con propiedad se dice xenodochium, nombre Hermida Lazcano recuerda, de mano de Covarrubias, que policía designa la "política, la ciencia y modo de gobernar la ciudad y república". Citemos, asimismo, una acepción que da de hospital: "lugar pío donde se reciben los peregrinos pobres, vel latine hospicium vel hospitale. Con propiedad se dice xenodochium, nombre griego $\xi \varepsilon v o \delta o \chi \varepsilon i o v$, locus publicus quo hospices, id est, peregrino excipiuntur". S. de Covarrubias Orozco, Tesoro de la Lengua Castellana o Española, Madrid, Castalia, 1995, p. 648.

${ }^{35}$ Cabe decir a este respecto que la estructura poblacional de los dos pueblos-hospitales quiroguianos tuvo una larga duración que se prolonga hasta su final en 1872, para Santa Fe de la Laguna, y en 1874, para Santa Fe de México, en un proceso de liberalización de la tierra. Serrano Gassent, op. cit., p. 229.

${ }^{36}$ R. Martínez Baracs, Convivencia y utopía, El gobierno indio y español de la ciudad de Mechuacan, 1521-1580, México, FCE, 2005, p. 219. En general esta obra es clave para la comprensión del devenir histórico de Michoacán en la temprana colonización española.
} 


\section{Los Saturna Regna de las “bucólicas”: la figura del Pastor y la expropiación militar}

En el capítulo tercero de la Información en derecho, Quiroga cita únicamente dos versos de las Bucólicas de Virgilio para apoyar la mención de la edad dorada de las Saturnales de Luciano de Samosata. Estos versos no hacen sino reiterar el tópos del mito de las Edades:

(iam redit et virgo), redeunt saturnia regna, iam nova progenies coelo demittitur alto ${ }^{37}$. (VI, 6,7$)$

Vuelve la Virgen ya, a reinar ya vuelve Saturno ya nueva raza nos es del alto cielo mandada ${ }^{38}$.

Ahora bien, como hipótesis de trabajo no nos conformaremos con la mera cita virgiliana y rastrearemos hasta qué punto podría estar operando una interpretación concreta de las Bucólicas en el pensamiento de Vasco de Quiroga o, al menos, qué correlaciones podríamos encontrar en sendos contextos. De este modo, analizaremos una serie de fragmentos de los poemas de las Bucólicas de Virgilio reinterpretándolos en el marco político que aquí nos ocupa, con clara correspondencia con lo antes dicho a colación de la referencia a Luciano.

El poema de Virgilio comienza con el diálogo entre dos pastores que pivota en torno al forzado desplazamiento fuera de sus tierras que sufren algunos pastores:

nos patriae finis et dulcia linquimus arva, nos patriam fugimus; $(\mathrm{I}, 3,4)$

lindes nosotros del pueblo y dulces surcos dejamos, patria perdemos nosotros;

donde los pastores, o el "nos" del latín, si se lee en clave histórica en el contexto de Virgilio, bien podrían ser todos los expropiados tras la repartición de tierras realizada por Octavio a sus veteranos de guerra. Mas en el contexto de Quiroga encontramos dos posibilidades, no excluyentes entre sí: por una parte, "pastor" nos remite al conjunto eclesiástico que fue al Nuevo Mundo con la misión de evangelizar, y podríamos situarlo en Quiroga en la Información en derecho, cap. 1.: "el verdadero pastor los informa, para que informen y hagan bien la guardia del ganado a ellos

\footnotetext{
${ }^{37}$ Citamos según Virgil, Eclogues, en "Virgil in two volumes" (vol I), Breat Britain, Loeb Classical Library, 1930.

${ }^{38}$ El paréntesis indica que Quiroga omite ese tramo. Citaremos la traducción de García Calvo, si bien para nuestro cometido hermenéutico se hace ineludible el trabajo sobre el original latino ante los matices que se pierden en la traducción. A. García Calvo, Virgilio, Madrid, Júcar, 1976, p. 143 y ss.
} 
encomendado" 39 , donde cita también el Evangelio según San Lucas "que los pastores velen por aquella región" (Lc. 2,8). Por otra parte, "pastor" designa a aquél que cuida una comarca o una tierra determinada, que en el poema virgiliano sufre la ocupación militar y que en el contexto de Quiroga podría traducirse en la expropiación de los indios realizada por los conquistadores españoles. Así, en Quiroga encontramos por doquier expresiones tales como "los verdaderos pobladores, cierto soy, ven claro lo que es: la total perdición de toda la tierra. Porque, aunque a aquéllos hincha las bolsas y pueble las minas, a estos verdaderos pobladores destruye y despuebla los pueblos" $"$, donde los verdaderos pobladores -los indios- que son tratados "como rebaños de ovejas, han de ser herrados quita las vidas con las libertades". Esto, podría remitirnos a los siguientes versos de Virgilio:

impius hace tam culta novalia miles habebit, barbarus has segestes? en quo discordia civis produxit miseros: his nos consevimus agros! (I, 70-72)

¿Un desalmado oficial tendrá tan arados barbechos? ¿Estas mieses un bárbaro? ¡Ay, discordia a los hombres, míseros, dónde los trae! ¡Para quién sembramos el campo!

$\mathrm{y}:$

O Lycida, uiui peruenimus, aduena nostri

(quod nunquam uereti sumus) ut possessor agelli

diceret: "Haec mea sunt; ueteres migrate coloni". (IX 2-4)

Lícidas, henos llegados con vida a que un forastero -lo que jamás temimos- de nuestra quinta adueñado diga: "Mío es esto, emigrad los viejos colonos".

En estos versos ocurre algo similar a la situación americana: los milites representan la conquista producida por "la codicia desenfrenada de nuestra nación"41, produciendo mediante tal discordia "la total perdición de toda la tierra", esto es, unos miseros civis $^{42}$, condenados a la huida o la esclavitud. Por tanto, los pastores bucólicos pueden servir doblemente para mostrar la necesidad de que esas tierras sean cui-

\footnotetext{
${ }^{39}$ Quiroga, op . cit., p. 72.

${ }^{40}$ Ibidem, p. 73.

${ }^{41}$ Ibidem, p. 79.

${ }^{42}$ El uso del término civis otorgaría en este contexto un matiz que no habría que descuidar, pues no es simplemente hombre o varón, pastor o agricultor, sino que literalmente apunta a quien habita la ciudad, al ciudadano, y en un contexto de pensamiento político y de configuración de una res publica indiana como el quiroguiano es evidentemente fundamental.
} 
dadas por el pastor eclesiástico y no por el miles, quien impide de veras el cuidado encomendado por la bula papal, así como para ser imagen de la situación del indio, expulsado de su propia tierra. De hecho, en la Ecloga I uno de los pastores -Títiroes esclavo y consigue comprar su libertad y mantenerse en sus tierras. Este hecho estaría en total consonancia con el argumento considerado, entre otros por Palacios Rubios o Matías de $\mathrm{Paz}^{43}$, acerca de la herencia española de una suerte de esclavos indios, naturales o por ius belli, desde el fondo del universalismo católico: dentro del despotismo paternal en algún momento el indio podría conseguir la libertad. Empero, este razonamiento, como ya hemos tratado, está desestimado en Quiroga para el que no hay esclavos naturales puesto que "sirven los unos a los otros no como esclavos como nosotros usurpadamente y corrupto el vocablo decimos, sino como hombres libres alquilados, que en derecho se llama este género de servicio locatio o venditio operarum in perpetuum (alquiler o venta de obras a perpetuidad)" "44. Sin embargo, si consideramos la adquisición de la libertas por parte de Títiro en el contexto del poema, encontramos quizá una de las claves interpretativas: Títiro narra a Melibeo cómo un dios le ha guarecido de la expropiación, así como cuenta su visita a Roma, la cual, según Títiro pensaba, sería canibus catulos similis (I, 22), esto es, como un cachorro respecto del perro adulto. Sin embargo, la ciudad sobresalía tanto en comparación con los lugares que los pastores conocían que de algún modo podríamos decir que es impropia una comparación meramente cuantitativa, es decir, la Urbs supone un cambio cualitativo en relación con las aldeas rurales. Pues bien, Melibeo pregunta a Títiro qué le llevó a ir a Roma, a lo que éste responde que la libertas. Entonces, si recorremos la línea interpretativa hasta aquí planteada, se nos presenta una situación idílica que se ve amenazada por la intromisión de los milites, cuya única buena salida, la libertad, entraña en el poema dos cuestiones: la primera, que deus nobis haec otia fecit (I, 6), esto es, "(un) dios nos entregó este sosiego", es decir, algo salvífico que dé consistencia a la vida; la segunda, para cumplimiento de la primera, ir a la ciudad (Vrbem quam dicunt Romam, I, 19) para conseguir la efectiva libertad. Por tanto, se puede concluir como hipótesis interpretativa que la idílica y amenazada situación necesita de deus y de la urbs, lo cual está en plena armonía con la noción de política mixta de Vasco de Quiroga en tanto que es necesario llevar a los indios el evangelio (es decir, que entren en contacto con deus) pero ello está mediado por el instalarlos en las costumbres ciudadanas, o lo que es lo mismo, en una res publica christiana. Esta relación se verá más claramente a través de la Ecloga IV.

\footnotetext{
${ }^{43}$ Palacios Rubios, De las Islas del mar Océano, y Paz, Matías de: Del dominio de los Reyes de España sobre los indios, México, Fondo de Cultura Económica, 1954.

${ }^{44}$ Quiroga, op. cit., p. 177.
} 
Redeunt Saturna regna, cita Quiroga, y esta vuelta significa el cumplimiento de la profecía de la Sibila de Cumas en un tiempo nuevo:

Vltima Cumaei uenit iam carminis aetas; magnus ab integro saeclorum nascitur ordo; $(\mathrm{IV}, 4,5)$

La Última Edad, que anunció la Sibila, hela llegada: ya de raíz nace nueva una grande rueda de siglos.

Tal profecía incluye un tipo excelso de personas que, además, están en un lugar concreto que es el Nuevo Mundo:

tu modo nascenti puero (quo ferrea primum

desinet ac toto surget gens aurea mundo (IV, 8, 9)

tú, a ese niño que nace, en quien la era de hierro terminará y brotará por el mundo el pueblo de oro

A este respecto dice Quiroga: "Nuevo Mundo no porque se halló nuevo, sino porque es en gentes y casi en todo como fue aquél de la edad primera y de oro, que ya por nuestra malicia y gran codicia de nuestra nación ha venido a ser de hierro y peor" ${ }^{45}$. No obstante, una vez que han confluido el Mundo Férreo y el Mundo Áureo, este tiempo nuevo no puede mantenerse por sí mismo porque, como antes vimos con Luciano, la codicia de los conquistadores rompería por completo este mundo.

Pauca tamen suberunt priscae vestigia fraudis, (VI, 31)

Pocas habrá pero huellas habrá del yerro primero.

que en este caso no serán precisamente pocas, por lo que se hace necesario el aprendizaje de la virtud con la consiguiente capacidad de juicio, ello procurado por el estudio de las gestas, que en el contexto de Quiroga no podría ser sino el conocimiento del evangelio y las Sagradas Escrituras:

At simul heroum laudes et facta parentis

iam legere et quae sit poteris cognoscere virtus, (IV, 26, 27)

Mas, de que ya las de los héroes tú y de tu padre las gestas puedas leer y saber cuál es el valor verdadero

\footnotetext{
${ }^{45}$ Ibidem, p. 101.
} 
Lo cual tendrá las siguientes implicaciones:

si qua manent sceleris uestigia nostri, inrita perpetua soluent formidine terras. (IV, 13,14)

toda huella que quede de nuestro pecado se borrará librando del miedo eterno la tierra.

así como:

pacatumque reget patriis uirtutibus orbem. (IV, 17)

ya apaciguado el confín reinará en la ley de su padre

Aparece que, de esta manera, para el mantenimiento del resurgimiento de la edad dorada se hace necesario que esa prole áurea aprenda a leer "las gestas del padre", de lo que se sigue la capacidad de discernimiento (cognoscere virtus), virtud que posibilita la justicia, que, a su vez, se concreta en un gobierno según las virtudes patrias o paternas, que borrarán las huellas de "nuestro pecado". Nuevamente, según la conjetura que venimos siguiendo de leer las Bucólicas en clave quiroguiana, se podría llegar a la conclusión de la mutua coimplicación de evangelización y civilización en tanto que la edad dorada entraña regir el orden según la ley paterna, que en este contexto se ha interpretado como conocer el evangelio y las ordenanzas ciudadanas, conformando la policía mixta. Además, "nuestro pecado" que una vez librado "borrará del miedo a la tierra", podría fácilmente identificarse con "nuestra malicia y gran codicia de nuestra nación", esto es, tanto con las barbaries concretas realizadas por los conquistadores, como también con la situación general en la que se encuentra el Viejo Mundo "de hierro".

\section{Antonio de Guevara y el "Relox de príncipes": edad dorada y plática contra la tiranía romana}

Vasco de Quiroga apenas cita ${ }^{46}$, y de manera tangencial, la obra de fray Antonio de Guevara, y, sin embargo, parece muy verídico pensar que la obra Relox de príncipes está usada en Quiroga en la misma estela que lo dicho acerca de Luciano, Moro o Virgilio, con el añadido de ser un autor más útil para la pragmática del texto al ser un hombre muy cercano a la corte de Carlos V. Quiroga hace referencia al célebre relato de "El villano de las riberas del Danubio a los senadores de Roma" ${ }^{47}$ cuyas fuentes son harto numerosas ${ }^{48}$, el cual sufre una reinterpretación en el contexto quiroguiano como crítica a la actuación de los conquistadores españoles. Por nuestra

\footnotetext{
${ }^{46}$ Ibidem, p. 82.

${ }^{47}$ Antonio de Guevara, Relox de príncipes, Madrid, Turner, 1994, libro III, cap. III-V.

${ }^{48}$ Vosters, op. cit., para la relación entre Guevara y Quiroga, p. 192.
} 
parte, también haremos referencia, aunque no hemos hallado la referencia explícita en el texto de Quiroga, a los capítulos en los que Guevara habla de la edad dorada y de "quándo començaron los tyranos a tyranizar"49. Las conclusiones a las que llegaremos ya han sido tratadas aquí, pero lo relevante del recurso a esta fuente estriba en su procedencia castellana y no grecolatina en tanto que entraña por parte de Guevara un recurso metódico que encontramos también en Quiroga, pese a que intención y contexto difieran. Este recurso consiste en criticar el presente o pasado próximo, acompañado o no de postular alguna alternativa, en virtud de la lectura del mundo clásico y de la tradición que precede al autor, de modo que cualquier clase de posicionamiento en esta estela de pensadores castellanos, sea o no novedoso, se produce en diálogo entre el contexto hispánico y el clásico. De hecho, con la vista puesta en el mundo romano, Quiroga viene a negar la esclavitud de los indios señalando que no es la misma situación que la romana, Vitoria se basa en la amicitia para legitimar la evangelización y el comercio mas no el dominio despótico, (en el sentido de que la única guerra legítima se produce cuando se violenta el comercio por parte del indio ${ }^{50}$ ), y, por último, Sepúlveda se inspira en el modelo militar para defender un despotismo tutelar. Pues bien, con el argumento de "el villano del Danubio", Quiroga puede ver en este relato no sólo una crítica a la actuación tiránica y al modo en que se juzga la gloria en la historia, sino también de algún modo un intento de cambio de la actitud del gobernante, ejemplificada en la modélica figura de Marco Aurelio, el emperadorfilósofo, como alguien capaz de aceptar escuchar críticas y rectificar en consecuencia. Esta capacidad de enmendar tendrá una intención especialmente relevante en el cometido quiroguiano, pero antes tratemos, aunque sea de un modo sucinto, el episodio del rústico Mileno, hombre del Danubio.

El relato narra cómo un germano increpa al Senado de Roma ante las múltiples injusticias cometidas por el expansionismo romano. Son muchos los rasgos del relato que podríamos tratar, pero señalaremos los que pensamos más relevantes para nuestro cometido. En primer lugar, una advertencia acerca de cómo se evalúan los hechos históricos: "os hago saber, si no lo sabéys, que al tiempo que los truhanes van delante los carros triumphantes diziendo: “¡Viva! ¡Viva la invencible Roma!”, por otra parte los pobres captivos van en sus coraçones diziendo a los dioses: “¡Justicia! ¡Justicia!” 51 , lo cual viene seguido más adelante de "ha sido tan grande vuestra codicia de tomar bienes ajenos, y fue tan desordenada vuestra sobervia de mandar en tierras estrañas, que ni la mar vos pudo valer en sus abismos, ni la tierra vos pudo assegurar en sus campos". La correlación con el contexto de Quiroga es evidente: la gloria de Castilla se construye

\footnotetext{
${ }^{49}$ Guevara, op . cit., libro I, cap. XXX y XXXI.

${ }^{50}$ Francisco de Vitoria, "Sobre los indios", en Sobre el poder civil, Sobre los indios, Sobre el derecho de la guerra, Madrid, Tecnos, 1998, $3^{\text {a }}$ parte.

${ }^{51}$ Guevara, op. cit., p. 635.
} 
sobre el yugo del indio, y se advierte de los excesos del expansionismo, no sea que del mantenimiento de la colonia se ponga en peligro la estabilidad de la tierra propia. $\mathrm{Si}$ bien la crítica va orientada a la opresión militar sin la contrapartida, operante en Quiroga, de la evangelización, en cambio, sí encontramos un argumento que cuestiona la dominación por la raza o pueblo, lo que sí estaría en consonancia con la consideración de la igualdad en dignidad entre todos los hombres, que bien podría recordar a los sermones de Fray Antonio de Montesinos ${ }^{52}$. Así escribe Guevara: "ni me da más que sea griego, que sea bárbaro, que sea romano; que esté absente, que esté presente; digo y afirmo que es y será maldito de los dioses y aborrecido de los hombres el que sin más consideración quiere trocar la fama con la infamia, la injusticia con la injusticia..."53. También encontramos argumentos en contra de la consideración del otro (del no-romano, pero también del no-español en el contexto quiroguiano) como un ser asocial o bruto. "Los que van allá nos toman la hazienda y los que estáys acá nos robáys la fama, diziendo que pues somos una gente sin ley, sin razón y sin rey, que como bárbaros incógnitos nos pueden tomar por esclavos", y continúa: "que digáys nosotros merescer ser esclavos a causa que no tenemos príncipe que nos mande, ni Senado que nos govierne, ni exército que nos defienda; a esto os respondo que, pues ni teníamos enemigos, no curávamos de exércitos, y que, pues era cada uno contento con su suerte, no teníamos necessidad de superbo Senado que governasse; que, siendo como éramos todos iguales, no consintíamos aver entre nosotros príncipes" ${ }^{4}$. Además, aparece un paralelismo muy claro entre el texto de Guevara y el de Quiroga, en torno a la causa de por qué los bárbaros parecen disgregados desde la perspectiva del conquistador: "que determino como malaventurado desterrarme de mi casa y de mi dulce compañía porque no vea con mis ojos cosa de tanta lástima. Más quiero andarme por los campos solo, que no ver mis vezinos cada hora llorando. Y, allende desto, los fieros animales, si no los ofendo, no me ofenden, pero los malditos hombres, aunque los sirvo, me enojan" 55 . Recordemos lo que advertía Quiroga acerca de los indios: "se espantasen con temores de guerra ni espantos de ella, porque, de no se fiar de nosotros ni de nuestra mala jacilla y conversación que tenemos, les viene el huir y alzarse a los montes por evitar los daños" $" 56$. Por ende, el uso de este relato muestra que el indio (o el bárbaro) es un ser social y político, igualmente humano, ergo también capacitado para aprehender el evangelio.

\footnotetext{
${ }^{52}$ Bartolomé de Las Casas, Historia de Indias, Biblioteca Virtual Miguel de Cervantes Saavedra, 2006, libro III, cap. IV-VI.

${ }^{53}$ Guevara, op . cit., p. 637.

${ }^{54}$ Ibidem, p. 643.

${ }^{55}$ Ibidem, p. 648.

${ }^{56}$ Quiroga, op. cit., p. 86.
} 
Por otra parte, el texto de Guevara introduce otra cuestión que se convertirá en un tema candente si lo consideramos desde la perspectiva de la relación de España con el mantenimiento de América: "yo no sé qué locura le tomó a Roma de embiar a conquistar a Germania; porque si lo hizo con cobdicia de sus thesoros, sin comparación fue más el dinero que se gastó en conquistarla y agora se gasta en sustentarla, que no le renta ni rentará por muchos años Germania, y podrá ser que primero la tenga perdida que no saquen la costa que hizieron por ella" ${ }^{57}$. Esta afirmación, que es el correlato desde la perspectiva del beneficio económico del anterior texto citado en sentido del gobierno político (la "sobervia de mandar en tierras estrañas"), podría caer como una losa en el imaginario castellano: no sólo no se está cumpliendo el mandato evangelizador de la bula papal, sino que además en lo que respecta al beneficio, la empresa de América supondrá la pérdida de la potencia española por mantener algo que finalmente le reporta más pérdida que ganancia.

Una vez más, como ya hemos tratado en Luciano y en Virgilio, la situación de injusticia generalizada se contrapone a una época en la que no había tantos crímenes, "porque mandar uno y obedecer otro es una de las novedades del mundo" donde "eran todas las cosas comunes en la república; porque entre los antiguos sólo las vidas tenían proprias, que las voluntades y haziendas todas eran comunes" $" 58$. La Arcadia, la edad dorada o el Paraíso terrenal, donde no hay crimen, pero no como ineludiblemente perdido, sino como dado de hecho en las Indias. En definitiva, no sólo está en juego el cumplimiento de la bula papal, sino también el destino al que se encamina el Viejo Mundo ante la nueva oportunidad de reconducir el descarriado espíritu cristiano en el dorado Nuevo Mundo.

Por último, pese a que en este último punto hemos mostrado algunos nexos de unión entre Guevara y Quiroga, es preciso criticar ciertas inferencias que en la historiografía se han realizado de esta relación. Nos referimos, por ejemplo, a Maravall, para quien "es prueba de la conexión de pensamiento entre Guevara, la corte de Carlos V y los que en Méjico intentaron encarnar una utopía" 59 . Pues si bien el vínculo textual entre ambos autores es claro, no lo es en modo alguno la prolongación ideológica que Maravall observa entre estos dos autores o, sin entrar a discutir aspectos específicos de Guevara, entre Quiroga y la política imperial de Carlos V. Nuestra disensión bascula en dos aspectos: el primero, que frente a la reiterada condena quiroguiana de la esclavitud, la prohibición de ésta de la Real Cédula apenas duro cuatro años, razón por la cual Quiroga efectuó independientemente su proyecto desde la compra de tierra con sus recursos y no como parte de un programa imperial de con-

\footnotetext{
${ }^{57}$ Guevara, op. cit., p. 641.

${ }^{58}$ Ibidem, p. 213.

${ }^{59} \mathrm{~J}$. A. Maravall, Carlos V y el pensamiento político del Renacimiento, Madrid, Instituto de Estudios Políticos, 1960, p. 204. En la misma línea: p. 228.
} 
quista y cristianización; el segundo, que ni el proyecto político quiroguiano era imperial, sino episcopal, ni la legitimación hispana sobre las Indias se producía por potestad universal del Emperador, sino por la concesión que daban las Bulas Alejandrinas bajo la justificación de la evangelización ${ }^{60}$. En definitiva, la conexión que establece Maravall la interpretamos en el sentido contrario: la práctica imperial española no deriva en la utopía quiroguiana, sino que Quiroga utiliza los relatos de alguien cercano a la corte como Guevara en un intento de cambiar el rumbo de la política imperial carolina.

\section{Conclusión}

A modo de excurso y antes de concluir, conviene esclarecer lo que, a nuestro parecer, es un exceso interpretativo consistente en la creencia de algunos autores contemporáneos de que Quiroga justificara, aunque fuera al final de su vida, la guerra justa contra los indios para su evangelización. Así, escribe Todorov -sin ninguna cita que nos remita a texto alguno- que Quiroga estimaba superior la forma de vida de sus pueblos-hospitales y que "para alcanzarla son válidos todos los medios: así, con Sepúlveda y contra Las Casas, es un defensor de las “justas guerras” contra los indios y del reparto de éstos en encomiendas feudales" ". Si analizamos los escritos de Quiroga, no encontraremos ni en la Carta al Consejo de 1531, ni en la Información en Derecho de 1535, ni en su Testamento de 1565, justificación de la guerra justa. Este mismo problema se encuentra en un escrito de Bataillon ${ }^{62}$, por el que seguramente esta tesis se haya extendido tanto, en el que se sostiene que Quiroga defiende la guerra justa, para lo cual recoge una carta de éste en la que se menciona un tratado suyo, De Debellandis Indis ${ }^{63}$, y se compara con el Parecer de fray Miguel de Arcos, en el cual se juzga la obra de un obispo que defiende la guerra justa, pero que no menciona a Quiroga. Las menciones en la carta de Quiroga a tal tratado no hacen ninguna referencia a la guerra justa, sino a la legitimidad de la posesión hispana de las tierras. Finalmente, los fragmentos editados como De debellandis Indis contradicen las tesis sostenidas por Quiroga en los textos claramente suyos, así como también con sus prácticas en los pueblos-hospitales y sus disputas con los encomenderos, que, recordemos, era el motivo de que Quiroga volviese a España de

\footnotetext{
${ }^{60}$ Acerca de las polémicas suscitadas a partir de la asociación entre la política imperial y las distintas figuras de la España carolina, véase: J. L. Villacañas, ¿Qué imperio?, España, Almuzara, 2008.

${ }^{61}$ Todorov, op. cit., p. 206.

${ }^{62}$ M. Bataillon, "Vasco de Quiroga y Bartolomé de las Casas", en Estudios sobre Bartolomé de las Casas, Barcelona, Ediciones Península, 1976.

${ }^{63}$ De Debellandis Indis, México, UNAM, 1988.
} 
1548 a $1553^{64}$. Por tanto, estimamos como error metodológico la atribución de defensa de la guerra justa a Quiroga sobre la base de un texto de dudosa autoría, más y cuando los textos en los que no cabe duda contradicen palmariamente esa tesis. No obstante, quedaría por tratar la acusación de Las Casas: "El obispo de Mechuacán donde quiere probar que se puede hazer la guerra a los indios para traellos a la fe"; acusación que no termina de comprender Quiroga: "salvo el Señor Obispo de Chiapa que no sé cómo lo ha tomado como no aya sido muy conforme a su rigor" 65 . A este respecto quizá esté operando una oposición añadida a la de conquistadores, encomenderos y clero, que será la existente entre las distintas agrupaciones de la Iglesia. Así tendríamos la polémica entre franciscanos y dominicos, representados, respectivamente, por Motolinía y Las Casas, y estos, en distintos grados, enfrentados con el episcopalismo de Quiroga y su defensa evangelización "profunda" a partir de las ciudades, frente a las evangelizaciones masivas de los franciscanos ${ }^{66}$. En definitiva, podemos pensar que la acusación de Las Casas esté enmarcada en la tensión propiciada por la Junta de Valladolid (1550-1551), así como por la disputa existente entre los diversos modos de entender la evangelización, pero ante las dudosas fuentes documentales, difícilmente se podría sostener la defensa de la guerra justa por Quiroga, ni mucho menos la sintonía con Sepúlveda.

Para finalizar, diremos que hemos intentado hasta aquí reconstruir el pensamiento de Quiroga en sus fuentes, para que se resitúe su obra no como mero relato descriptivo que reflejara la bondad de ánimo del obispo sobre los indios, sino como un claro proyecto político que confería a la construcción de un marco jurídico un papel fundamental en la evangelización, así como un método viable para organizar una población dispersa y desestructurada por la total quiebra social que supone la llegada del dominio de los conquistadores. Casi al comienzo de este trabajo trajimos a colación el célebre texto de Todorov, en el que se manifestaba la falta de consideración del indio como verdadero sujeto interlocutor, y cómo la relación con el otro se dividía usualmente en subyugación esclavista, o asimilación e identificación cristiana; en definitiva, un vínculo en el que en todo momento se partía de la superioridad hispana. Raras veces, y originado por circunstancias accidentales, se producía una inmersión del español en el mundo indígena, cuyos máximos ejemplos están en Álvar Núñez Ca-

\footnotetext{
${ }^{64}$ Acerca del estado de la cuestión sobre el De Debellandis Indis, véase: Serrano Gassent, op. cit., p. 378-389.

${ }^{65}$ Bataillon, op. cit., p. 269.

${ }^{66}$ De hecho las tensiones entre Quiroga y las órdenes fueron continuas como recoge Gaudot, citando la Carta de Vasco de Quiroga al Consejo de Indias del 22 de marzo de 1560: “... se tiene por cierto los religiosos de las tres órdenes mendicantes que residen en esta Nueva España escriben a S. M. y a esse consejo rreal y aún según ellos dizen hasta Roma al Papa los agravios que dizque les hazemos los obispos primeros desta tierra". G. Baudot, Utopia and History in Mexico, Colorado, University Press of Colorado, 1995, p. 319 (n. 191).
} 
beza de Vaca y, de un modo especial, en Gonzalo Guerrero, de quien se dice que llegará a luchar en el bando maya en contra de los españoles. Asimismo, vimos que la postura de Quiroga era asimilacionista, pero ya el hecho de que ciertos puestos de poder los ejercieran los indios era una cierta fusión de caracteres, aunque ésta se produjera desde el desdibujarse de la cultura precolombina de estos y para asumir la estructura hispana manteniendo, en la medida de lo posible, una cierta jerarquía precolombina de pequeños caciques ahora como patres familias. También hay que tener en cuenta la consideración de la lengua del otro, como por ejemplo en la comparación hecha por Quiroga entre "el villano del Danubio" y el ruego de unos niños indios: "con tantas lástimas y encarecimientos y buenas maneras de decir, que hizo la plática llorar..." ${ }^{97}$, y el acercamiento cultural que conlleva el sobrecogido reconocimiento de la elocuencia de estos al hablar su lengua. Otro ejemplo dentro de su obispado está en el estudio de la lengua purépecha para una mejor consecución de la evangelización, como es el caso del fraile franciscano Maturino Gilberti que escribió un Arte de la lengua de Michuacán, así como un Diálogo de Doctrina Cristiana escrito en tarasco (purépecha), que posteriormente será censurado por el propio Quiroga por cuestiones de desavenencia doctrinal ${ }^{68}$. No obstante, quizá una de las claves para interpretar a Quiroga no esté en el plano de subyugación-asimilación en la ausencia de reconocimiento del otro como interlocutor como vimos en Todorov, sino en el análisis del tratamiento al excluido en la cultura hispánica, lo cual nos remite no sólo a la experiencia de Quiroga en Orán con moriscos y judíos, sino también, analizando las fuentes castellanas contemporáneas en su obra, al pensamiento conciliarista y con éste el converso, ambos muy extendidos $-\mathrm{y}$ a menudo identificados en los mismos agentes- en la Castilla de la centuria anterior, lo que a su vez incluirá en el pensamiento político de las Comunidades. Todas estas cuestiones, que desbordan el presente escrito y que trataremos en otra publicación en curso, confluyen y se articulan en el llamado Tata Vasco a través del utopismo y el mito de la edad de oro. En definitiva, el intento de conformar un conjunto de repúblicas y de pensar otra España y, con ello, otro modo de relacionarse con América. Esfuerzos estos frustrados, pues para entonces el negocio del material humano era ya imparable y alojado en el corazón mismo del sistema económico imperial.

\footnotetext{
${ }^{67}$ Quiroga,op. cit., p. 82.

${ }^{68}$ Zavala, op. cit., p. 226 y p. 290. Por otra parte, es probable que jugara un papel en esta desavenencia la dura oposición que plantearon los franciscanos al proyecto tutelar-episcopal de Quiroga.
} 